\title{
Study Demands, Social Support and Mental Health in Teacher Education Students: A Cross-Sectional Study
}

\author{
Mia Söderberg'
}

\author{
Eva M Andersson ${ }^{1}$
}

\section{Lisa Björk ${ }^{2}$}

\section{Gunilla Wastensson ${ }^{1}$}

\author{
${ }^{1}$ Occupational and Environmental Medicine, \\ School of Public Health and Community Medicine, \\ Institute of Medicine, University of Gothenburg, \\ Gothenburg, Sweden \\ ${ }^{2}$ Institute of Stress Medicine, West Region of Sweden, \\ Gothenburg, Sweden
}

Doi: 10.36941/jesr-2020-0040

\begin{abstract}
The aim of this paper was to investigate relationships between psychosocial factors in a study environment and mental health in teacher education students. Study objectives were explored in 593 Swedish teacher education students (80\% women). Psychosocial variables were measured with the standard Swedish demandcontrol-support questionnaire. Associations to mental health were calculated with logistic regression analyses, stratified by gender. Female students, on average reported higher demands, exhaustion and anxiety, than men. High study demands were associated with severe exhaustion in both men and women, even in models including all potential confounders and social support. Although, social support was related to lower exhaustion in women and less anxiety in men, this variable only contributed to minor effect changes in the associations study demands to mental ill-health. High study demands seem important for mental health in teacher education students. Future studies, perhaps using qualitative methods, would benefit the state of knowledge regarding students' psychosocial conditions and poor mental health. Such knowledge could assist universities in interventions to enhance both health status and future stress resilience.
\end{abstract}

Keywords: Teacher education students; Psychosocial study demands; Social support; Mental health

\section{Introduction}

The prevalence of adverse mental health in higher education students, in this paper defined as college and university students, is high in most Western countries. Two review papers have shown that $8-23 \%$ of students report depression on a clinical level (Garlow et al., 20o8; Rotenstein et al., 2016) and that $27-38 \%$ suffer from moderate to severe anxiety (Andrews \& Wilding, 2004; Dyrbye, Thomas, \& Shanafelt, 2006). In some populations, a conspicuous $11 \%$ of the study subjects even displayed suicidal tendencies (Garlow et al., 2008; Rotenstein et al., 2016). It has been argued that an augmented prevalence is explained by worse mental health in young adults in general, since they are 
undergoing a transition period in life (Stewart-Brown et al., 200o). However, university students display significant higher levels of depressive and anxiety symptoms compared to aged-matched individuals in the general population (Dyrbye et al., 2006; Roberts, Golding, Towell, \& Weinreb, 1999; Stewart-Brown et al., 200o). Other hypotheses stipulate that university students is a selected group with high internal demands for success or that mental health issues relates to an initial reaction of adjusting to an university setting (Zoccolillo, Murphy, \& Wetzel, 1986). Contrary, longitudinal studies have shown that psychological illnesses occur even in subjects without symptoms before entering the university and increase with time spent in an educational programme (Aktekin et al., 2001; Andrews \& Wilding, 2004; M. Dahlin, 2007). For example, in one large British study including 16,460 students (Bewick, Koutsopoulou, Miles, Slaa, \& Barkham, 2010), the mean depression scores were almost doubled at a three-year follow-up, compared to before registration.

In two review studies, the most adverse factor in higher education was considered to be a high workload, constituting of studying for exams, writing essays, meeting deadlines and practical training (Robotham, 2008; Robotham \& Julian, 2006). Unfortunately, findings are difficult to compile, since study demands has been measured with a wide range of different and rarely validated instruments, and often focusing on particular aspects of the study environment, rather than the overall sum of demands. Most studies also focused on the perception of stress, rather than on study environment dimensions. One of the leading models for measuring psychosocial conditions in a work setting is the job demand-control-social support model (R. A. Karasek, 1979; R. A. Karasek \& T. Theorell,1992). The demand dimension is mainly operationalized in terms of work load and intensity. Job control specifies to what extent the individual can influence the order, volume and content of their tasks, but traditionally also includes the component skill discretion, which measures stimulation and learning of new skills. Social support includes both emotional and instrumental support i.e. help with work task (Johnson \& Hall, 1988) and is hypothesized to buffer negative effects from high demands. Out of these variables, substantial evidence relates high demands to depression, anxiety and exhaustion (Häusser, Mojzisch, Niesel, \& Schulz-Hardt, 2010; Stansfeld \& Candy, 2006; Van der Doef \& Maes, 1999). Job control and social support have displayed more conflicting results in regards to mental health, but social support has been linked to general psychological well-being (Stansfeld \& Candy, 2006; Van der Doef \& Maes, 1999).

Furthermore, psychosocial demands and health in students have primarily been investigated in clinical or social care educations (Dyrbye et al., 2006; Robotham, 2008; Rotenstein et al., 2016; Shapiro, Shapiro, \& Schwartz, 200o). This focus stems from presumptions of a high total workload, including both pressures of acquiring knowledge and passing exams, as well as responsibilities and emotional demands from practical training. Teachers' educational programmes also involve practical training, putting theory into practice and establishing a professional role towards pupils and their parents, but knowledge of psychosocial conditions and health is lacking in this student group. The need for knowledge may be illustrated by a recent report from one of the largest universities in Sweden (University of Gothenburg) (Akademihälsan, 2014). The report showed that the Faculty of Education had the highest percentage of students with health care needs (11\%), which even surpassed the medical faculty. Additionally, a report from the Swedish higher education authority (Svensson \& Berlin Kolm, 2017) illustrated that $35 \%$ of all students that enter a teacher education programme, terminate their studies before obtaining a master degree, which is the highest drop-outs rate of all university programmes. Underlying reasons can only be speculated in. Fears of not coping with stress as a teacher may be one reason, but the high need for health care among teacher students at the University of Gothenburg, may indicate that a stressful study situation also contributes.

Furthermore, teachers are an occupational group that, especially in later years, has displayed high prevalence of mental health issues related to stress and burnout (Khan, Yusoff, \& Khan, 2014), and it's therefore important to investigate if a downward spiral of adverse mental health begins already as a student. A few studies support this, as it has been found that beginning teachers display high levels of burnout already during their education (Gavish \& Friedman, 2010) and that poor mental health during education, in general, is associated with future burnout (Vasalampi, Salmela-Aro, \& 
Nurmi, 2009). As high demands have been identified as predictor for adverse mental health in a job setting, this important variable need to be evaluated in a student setting using well-established instruments. Positive buffering effects from social support has not been investigated either, which is surprising, since a student situation commonly is characterized by a rich social life. This study aims to explore relationships between study demands and mental health outcomes, exhaustion, anxiety and depression, in education students, and whether social support affects these associations. By using standard instruments to measure psychosocial study conditions, we enable comparisons to the existing literature. To detect gender differences, we will also stratify analyses by gender.

\section{Methods}

\subsection{Study population}

The data analysed in this paper is the baseline data from a prospective cohort study on stress and health in Swedish teachers. Participants were recruited from seven south-western Swedish universities. Inclusion criteria constituted all education students attending the last semester of an educational programme leading to a certificate as a fully qualified primary or secondary school teacher. Eligible students were identified through the Swedish higher education registration system (LADOK), and sent a questionnaire, an information letter and a web-link to the questionnaire in digital format, by post. Data collection was carried out throughout April 2015 to November 2016.

Of the 1485 students who fulfilled the inclusion criteria and were invited to participate in the study, 637 subjects filled in and returned the questionnaire (response rate $=43 \%$ ). We excluded all who had responded to fewer than half of the items in any main variable or had missing responses on 1-item variables $(n=41)$. Of the remaining participants, three persons identified themselves as a gender other than man or woman. These subjects constituted a small group, and therefore regression analyses could not be carried out in this subsample. The small number also meant that anonymity could not be guaranteed, and they were consequently deleted. The final sample used for analyses consisted of 593 subjects (80\% women).

\subsection{Measures}

The questionnaire recorded basic demographic information, number of children at home, work in paid employment, smoking and alcohol habits, physical activity, psychosocial study conditions, personality traits, general health and mental health.

Commonly when examining demands, buffering effects from amount of control is also analysed. We have, however, omitted control as this variable contains the dimension "skill discretion", i.e. learning new skills. As the main focus of an educational programme, unlike to a work situation, is to obtain new knowledge, the use of this variable would be misleading.

\subsubsection{Demands}

Study demands was measured using the five demand items from the Swedish version of the standard Job Content Questionnaire (R. Karasek et al., 1998), labelled The Swedish Demand-Control-Support Questionnaire (DCSQ) (Sanne, Torp, Mykletun, \& Dahl, 2005). The Likert-type response scale for all five items ranged (1-4) from "Yes, often" to "No, almost never". Since the original instrument evaluates demands in a work setting, the wording was changed from "your job" and "your work situation" to "your studies" and "your study situation". For the purposes of analysis, all demand items were positively inverted, so that high scores equated with high demands, and then summed up. 


\subsubsection{Social support}

Social support from students and faculty members was also captured with the DCSQ (Sanne, Torp, et al., 2005), using the standard six items. The response options, on a Likert-type scale, ranged (1-4) from "Completely agree" to "Completely disagree". The wording was changed from "At your workplace" and "My colleagues" to "At my college/university" and "My fellow students". Similar to job demand, all items were positively inverted and summed up.

\subsubsection{Exhaustion}

Exhaustion was measured with the Shirom-Melamed Burnout Questionnaire (SMBQ) (Melamed, Kushnir, \& Shirom, 1992), which consists of 22 questions, with response options that ranged on a scale (1-7) from "Almost never" to "Almost always". The answers were inverted so that a high score corresponded to high burnout, then summed and divided by the number of items in the instrument, generating an index. In the statistical analyses the sample was dichotomized according to a standard cut-off (Lundgren-Nilsson, Jonsdottir, Pallant, \& Ahlborg, 2012), where scores $\geq 4.47$ indicate "Severe levels of exhaustion".

\subsubsection{Anxiety and depression}

To estimate symptoms of anxiety and depression we used the Hospital Anxiety and Depression Scale (HAD) (Lisspers, Nygren, \& Söderman, 1997). This instrument consists of seven items measuring depression and seven items measuring anxiety, each with four response options on a scale of o-3, but with different response formats for each question. Total scores were calculated separately for anxiety and depression. According to standard categorization, a score of o-6 reflects low levels of anxiety/depression, 7-10 points mild to moderate levels, and $\geq 10$ indicates severe anxiety or depression. Both scores were dichotomized at $\geq 10$ points. However, very few participants had depression scores above the standard cut-off; hence, associations between depression and psychosocial variables were not analysed.

\subsubsection{Confounders}

Confounders used in the analyses were age, number of children at home, being born in Sweden, working extra in paid employment, at least one parent with university education, general health, physical activity and performance-based self-esteem. Age was allowed to have a non-linear association with the outcome by adding age squared. The variables "being born in Sweden", "working extra" and "at least one parent with higher education" were dichotomized into "yes" or "no". We also adjusted for general health, measured with one item from the Short Form 36 Health survey (SF-36) (Ware Jr \& Sherbourne, 1992), with five response options on a scale of ${ }_{1-5}$, ranging from "Poor" to "Excellent". Due to a very skewed distribution for this variable, some categories were combined. For women the response options "Poor" and "Somewhat poor" were treated as one category. For men the response options "Poor" and "Somewhat poor" were treated as one category, and the remaining responses then constituted the other category. Another potential confounder was physical activity, measured with the Saltin-Grimby Physical Activity Level Scale (Saltin \& Rowell, 1980), consisting of one item with a response scale (1-4) from "Being almost completely inactive" to "Regular hard physical training for competition sports". Since previous studies have shown that self-rated demands and health in students might partly relate to personality traits (Abouserie, 1994; M. Dahlin, Joneborg, \& Runeson, 2007), we also adjusted our calculations for performance-based self-esteem, estimated with the Performance-based Self-esteem Scale (Hallsten, Josephson, \& Torgén, 2005), which was analysed as a continuous variable. 


\subsection{Statistical analysis}

Missing values were handled as follows: for subjects with $>50 \%$ missing items per variable or missing values in one-item variables, the subject was not included in the analyses. Missing values with $<50 \%$ missing items per a variable, were imputed. Imputed values were based on each participant's mean scores of the remaining items in each variable. Differences between men and women regarding psychosocial and mental health variables were tested using t-test for independent groups. Associations between the psychosocial variables and mental health outcomes were analysed using logistic regression. Pearson's correlation coefficient was used to assess possible multi-collinearity. Three regression models were estimated: model 1 was unadjusted and included only the variable demand, model 2 included all chosen confounders and model 3 included social support in addition to all confounders. In the regression analyses, both demand and social support levels were specified according to the interquartile range. Results showing the association between demand and the outcome (exhaustion or anxiety) were presented as odds ratios. All regression analyses were stratified by gender. P-values <0.05 (two-sided tests) were considered significant.

\section{Results}

The sample used for analyses consisted of 593 participants ( $80 \%$ women), characteristics of the sample in Table 1.

Table 1: Characteristics of the sample

\begin{tabular}{lcc}
\hline & Men & Women \\
\hline $\mathrm{N}(\%)$ & $118(19.9)$ & $475(80.1)$ \\
\hline Age, mean (SD) & $30.6(7.1)$ & $28.4(6.1)$ \\
\hline Children at home, N (\%) & $93(78.8)$ & $361(76.0)$ \\
\hline None & $21(17.8)$ & $87(18.3)$ \\
\hline 1-2 children & $4(3.4)$ & $27(5.7)$ \\
\hline$\geq 3$ children & $108(91.5)$ & $445(93.7)$ \\
\hline Born in Sweden, N (\%) & $85(72.0)$ & $317(66.7)$ \\
\hline Working extra, N (\%) & $61(51.7)$ & $233(49.1)$ \\
\hline University-educated parent, N (\%) & $1(0.9)$ & $5(1.1)$ \\
\hline General health, N (\%) & $11(9.3)$ & $33(7.0)$ \\
\hline Poor & $34(28.8)$ & $163(34.3)$ \\
\hline Fair & $55(46.6)$ & $208(43.8)$ \\
\hline Good & $17(14.4)$ & $66(13.8)$ \\
\hline Very good & $11(9.3)$ & \\
\hline Excellent & $44(37.3)$ & $202(42.5)$ \\
\hline Physical activity & $46(39.0)$ & $175(36.8)$ \\
\hline Inactive & $17(14.4)$ & $43(9.1)$ \\
\hline Light activity & $41(34.8)$ & $219(46.1)$ \\
\hline Regular activity/training & $3.1(1.1)$ & $3.4(1.2)$ \\
\hline Regular hard training & &
\end{tabular}

Women reported slightly higher study demands than men, while the social support from other students or members of the faculty did not differ between genders (Table 2). Overall, $24 \%$ of the students reported severe anxiety, and $4.6 \%$ severe depression. Female students displayed somewhat higher levels of exhaustion and anxiety than men. In a similar fashion, a larger share of women 
displayed severe exhaustion or anxiety. Mean scores in depression did not differ significantly between genders, and students with severe levels of depression were few.

Table 2: Psychosocial study conditions and mental health by gender

\begin{tabular}{lcccc}
\hline & Men & Women & $\begin{array}{c}\text { Range } \\
\text { Min-max }\end{array}$ & P-value \\
\hline Psychosocial variables & & & & \\
\hline Demands, mean (SD) & $11.6(2.7)$ & $12.3(2.8)$ & $5-20$ & 0.01 \\
\hline Social support (SD) & $19.2(2.8)$ & $18.8(2.9)$ & $6-24$ & 0.2 \\
\hline Mental health variables, mean (SD) & & & & \\
\hline Exhaustion & $3.2(1.1)$ & $3.4(1.3)$ & $1-7$ & 0.03 \\
\hline Anxiety & $6.8(4.3)$ & $8.0(4.4)$ & $0-21$ & 0.01 \\
\hline Depression & $3.5(3.0)$ & $3.8(3.3)$ & $0-21$ & 0.4 \\
\hline Mental health variables, N (\%) & & & & \\
\hline Exhaustion, scores $\geq 4.47$ & $14(11.9)$ & $114(24.0)$ & & \\
\hline Anxiety scores $\geq 10$ & $23(19.5)$ & $121(25.5)$ & & \\
\hline Depression scores $\geq 10$ & $4(3.4)$ & $23(4.8)$ & & \\
\hline
\end{tabular}

The multiple logistic regression analyses (Table 3) illustrated that study demands were associated with notably increased odds ratios for severe exhaustion in both women (OR 2.8; CI 95\% 1.8-4.2) and men (OR 5.2; CI 95\% 1.6-16.6), even when adjusting for all chosen confounders and adding social support. The odds ratios were higher in men, but results also displayed wide confidence intervals. Social support, included in model 3, was linked to less exhaustion in women (OR o.6; CI 95\% 0.4o.8), but only had minor effects on the relationship of demands to exhaustion, regardless of gender.

Table 3: Association between exhaustion and psychosocial variables

\begin{tabular}{|c|c|c|c|c|c|}
\hline \multirow[b]{2}{*}{ Psychosocial variables } & & \multicolumn{2}{|c|}{ Men } & \multicolumn{2}{|c|}{ Women } \\
\hline & & Odds ratio $^{\mathrm{a}, \mathrm{e}}$ & $\begin{array}{c}\text { CI 95\% } \\
\text { (p-value) }\end{array}$ & Odds ratio $^{\mathrm{a}, \mathrm{e}}$ & $\begin{array}{c}\text { CI 95\% } \\
\text { (p-value) }\end{array}$ \\
\hline Model $1^{b}$ & Demands & $4 \cdot 4$ & $\begin{array}{l}1.6-12.3 \\
(0.005) \\
\end{array}$ & 2.9 & $\begin{array}{c}2.0-4.1 \\
(<0.0001)\end{array}$ \\
\hline Model $2^{c}$ & Demands & 5.0 & $\begin{array}{l}1.5^{-16.3} \\
(0.007)\end{array}$ & 3.0 & $\begin{array}{c}1.9-4.5 \\
(<0.0001)\end{array}$ \\
\hline \multirow{2}{*}{ Model $3^{d}$} & Demands & 5.2 & $\begin{array}{c}1.6-16.6 \\
(0.006)\end{array}$ & 2.8 & $\begin{array}{c}1.8-4.2 \\
(<0.0001)\end{array}$ \\
\hline & Support & 0.6 & $\begin{array}{c}0.2-1.6 \\
(0.33)\end{array}$ & 0.6 & $\begin{array}{l}0.4-0.8 \\
(0.003)\end{array}$ \\
\hline
\end{tabular}

a The odds ratio for Demands shows the association between the outcome exhaustion and the score for demands, per 4 units of the demands score (the interquartile range is 4). b Model 1 Unadjusted, including only Demands. c Model 2 Adjusted for age, children at home, born in Sweden, working extra in paid employment, parent with higher education, general health, physical activity and performance-based self-esteem. $\mathrm{d}$ Model 3 All confounders in model $2+$ social support. e The odds ratio for Support is presented per 4 units of the support score (the interquartile range is 4 ).

Study demands were associated with increased anxiety (OR 1.5; CI 95\% 1.0-2.1) (Table 4), but only in women. Social support among female students, included in model 3, was not related to anxiety, nor did adding the variable change the effects of study demands. In contrast to women, study demands were not related to increased anxiety in male students, instead social support was associated with lower odds ratios for anxiety (OR 0.4; CI 95\%, o.2-0.97). 
Table 4: Association between anxiety and psychosocial variables

\begin{tabular}{|c|c|c|c|c|c|}
\hline \multirow[b]{2}{*}{ Psychosocial variable } & & \multicolumn{2}{|c|}{ Men } & \multicolumn{2}{|c|}{ Women } \\
\hline & & Odds ratio ${ }^{\mathrm{a}, \mathrm{e}}$ & $\begin{array}{c}\text { CI 95\% } \\
\text { (p-value) }\end{array}$ & Odds ratio $^{\mathrm{a}, \mathrm{e}}$ & $\begin{array}{c}\text { CI 95\% } \\
\text { (p-value) }\end{array}$ \\
\hline Model $_{1}^{b}$ & Demands & 1.6 & $\begin{array}{c}0.8-3.2 \\
(0.09)\end{array}$ & 1.6 & $\begin{array}{l}1.2-2.2 \\
(0.002)\end{array}$ \\
\hline Model $2^{c}$ & Demands & 1.5 & $\begin{array}{c}0.6-3.5 \\
(0.36)\end{array}$ & 1.5 & $\begin{array}{c}1.0-2.1 \\
(0.03)\end{array}$ \\
\hline \multirow{2}{*}{ Model $3^{d}$} & Demands & 1.8 & $\begin{array}{c}0.7-4.5 \\
(0.2)\end{array}$ & 1.5 & $\begin{array}{l}1.0-2.1 \\
(0.03)\end{array}$ \\
\hline & Support & 0.4 & $\begin{array}{c}0.2-0.97 \\
(0.04)\end{array}$ & 0.9 & $\begin{array}{c}0.7-1.3 \\
(0.7)\end{array}$ \\
\hline
\end{tabular}

a The odds ratio for Demands shows the association between the outcome anxiety and the score for demands, per 4 units of the demands score (the interquartile range is 4). b Model 1 Unadjusted, including only Demands. c Model 2 Adjusted for age, children at home, born in Sweden, working extra in paid employment, parent with higher education, general health, physical activity and performance-based self-esteem. $\mathrm{d}$ Model 3 All confounders in model $2+$ social support. e The odds ratio for Support is presented per 4 units of the support score (the interquartile range is 4 ).

\section{Discussion}

We observed a moderate prevalence of severe exhaustion and anxiety in teacher education students and that high study demands, measured with a validated standard instrument (Sanne, Torp, et al., 2005), were linked to both exhaustion and anxiety. Although social support, a typical feature of students' lives, displayed positive effects, this variable, surprisingly, did not modify effects between study demands and mental health outcomes. Some gender differences were also noted, as women reported higher average exhaustion and anxiety, and study demands were only related to anxiety in women.

Our study results of associations between high study demands and mental ill-health, are coherent with the existing literature on higher education students (Robotham, 2008; Robotham \& Julian, 2006), despite that study demands previously has been measured with non-validated instruments and including a broad variety of specific demands, rather than overall demands. Results were also similar to established relationships between high demands and exhaustion in working populations (Häusser et al., 2010; Stansfeld \& Candy, 2006; Van der Doef \& Maes, 1999). Odds ratios were higher in men, but results displayed wide confidence intervals, likely caused by few men with severe exhaustion $(n=14)$, and are less reliable. Associations between demands and anxiety were only significant in female students. Few studies have investigated anxiety and stratified results by gender. One study (Sanne, Mykletun, Dahl, Moen, \& Tell, 2005), measuring demands and anxiety with the same instruments as in the present study, found similar results regarding gender differences, which indicates that there are dissimilarities either in exposure or perception of stressing conditions and anxiety.

Furthermore, social support is a proven positive factor in the occupational health literature, both as an individual factor and as a buffer against detrimental effects from a high workload (Eller et al., 2009; Stansfeld \& Candy, 2006). Even though social support was associated with lower exhaustion and anxiety, adding this variable had little or no effect on associations between study demands and health outcomes. The lack of effects for social support accentuates the strong association between pressuring study demands and mental illnesses.

Although not dramatically different, women reported significantly higher study demands than men, which corresponds with other studies, especially in students training for jobs with patient or client responsibilities (M. Dahlin, 2007; M. Dahlin, Joneborg, \& Runeson, 2005; M. E. Dahlin \& Runeson, 2007). There are many theories of underlying reasons for such tendencies, some argue that 
reports of higher demands in women relate to a stronger drive to be prepared for their upcoming occupations. For example, women in medical training have displayed more concerns about future responsibilities than male students (M. E. Dahlin \& Runeson, 2007). Women also showed slightly increased average scores of exhaustion and anxiety than men. This may be related to higher study demands or over all life stress, due to often being the main caretaker in a household (Hall, 1992). It also reflects tendencies in the general population, where women tend to more frequently report symptoms of anxiety (Lager, 2009:8). Differences may also stem from men's lower inclination to identify or acknowledge psychological health problems (Galdas, Cheater, \& Marshall, 2005), leading to underreporting of mental issues and results that are skewed to healthier scores. Men displayed considerably higher odds ratios for exhaustion than women, but confidence intervals were wide. Possibly since men tend to only report mental health issues when these are severe, resulting in higher variability and large odds ratios.

It has been hypothesized that young adults, due to being in a transitional phase in their lives, are more disposed to psychological disorders. In comparison to a cohort of young adults aged 25-34 years, drawn from the general Swedish population in 2004 (Norlund et al., 2010), the education students reported higher levels of exhaustion, especially female students: $24 \%$ of the women in this study reported severe exhaustion, compared to $16 \%$ in the study from 2004. The students also displayed higher mean anxiety scores $($ men $=6.8$ and women $=8.0$ ) than the normative values for the HAD scale (mean value for both genders=4.6) (Lisspers et al., 1997). However, the comparative data mentioned were collected 13 and 20 years ago, and it is therefore unknown whether worse mental health in education students relates to variables specific to higher education or whether dissimilarities are the result of changes in health in young adults in general.

The main purpose of the universities is traditionally knowledge dissemination and training for developing professionally. A current discussion, when poor mental health in young adults are on the rise, is whether universities should have increased responsibilities in protecting health among its students and work with improving study environment on a routine basis or even provide stress management programmes. Considering the increased and high prevalence of stress-related ill-health and long-term sick leave among teachers (AFA-försäkring, 2016; Försäkringskassan, 2010; Lidwall, 2015), targeted interventions for stress resilience could benefit both the students, as well as promote long lasting coping mechanisms for stress and increase a healthy working life. But in order to do this more knowledge on key factors in the psychosocial study environment is needed.

\subsection{Methodological considerations}

Although it is an advantage to use a validated instrument, the DCSQ (Sanne, Torp, et al., 2005) is adapted to work environments. Furthermore, the variable "control", a standard variable in DCSQ, was not investigated, the reason being that control is constituted by two sub-dimensions, skill discretion and decision authority, where skill discretion evaluates acquisition of new skills and knowledge. Measuring skill discretion would be maladjusted in this study, as the main purpose of higher education is to gain new knowledge. Furthermore, previous studies in university students and primary/secondary school pupils have noted that this dimensions is still a central part of psychosocial conditions in both settings and that there is support that the JDCS model is robust over different settings and age groups (Gillander Gadin \& Hammarström, 2003; Sonmark \& Modin, 343 2017). The university is the students workplace, and they encounter similar features as adults, such as a needing to execute a certain amount of tasks, meeting deadlines, and receiving feedback on performed work. Consequently, the health implications of the psychosocial conditions students meet can in many ways be expected to resemble those of adult employees.

No previous studies on mental health in teacher education students were found, and our results are furthermore not entirely comparable to the available literature on students in general, due to our stricter definition of mental illness. Review studies have observed a prevalence of $27-38 \%$ of "moderate to severe anxiety" in students in various types of higher education (Andrews \& Wilding, 
2004; Dyrbye et al., 2006) compared to this study, where $24 \%$ of the students had "severe anxiety". The HAD scale (Lisspers et al., 1997) used in the present study does not include a standard cut-off for moderate anxiety, but rather use one cut-off for "mild to moderate" anxiety. Since we were interested in more serious states of mental ill-health we used the cut-off for "severe anxiety".

Additionally, a smaller share of subjects experienced severe depression in this sample (4.6\%) compared to other studies (8-23\%) (Garlow et al., 2008; Rotenstein et al., 2016). The difference could, as with anxiety, be based on dissimilarities in categorization criteria. It may also be related to characteristics of depression, such as low energy or difficulties concentrating. The subjects in this study were attending the last semester of their educational programme, and those with severe depression may already have been filtered out.

\subsection{Limitations}

One of the study's major shortcomings is the low response rate (43\%), particularly among men (34\%). Although it is generally accepted that young adults are harder to recruit to scientific studies and the sample size was large enough to conduct our analyses, the response rate limits the study's external validity. We had background data on gender (man/woman), age at baseline, university and educational programme (primary/secondary) for 1483 (out of 1485) students who were sent a study invitation. $\mathrm{Chi}^{2}$ tests and t-tests showed that there were significantly different response frequencies between men and women $(\mathrm{p}<0.0001)$, but since men and women are analysed separately, the dominant share of women will not skew the results. The low response rate in male students, does however, lowers generalization. Further, there were significantly different response frequencies for different universities $(\mathrm{p}=0.01)$ and educational programmes $(\mathrm{p}=0005)$. Those universities and educational programmes with highest response rates will dominate the results. We do not have information of differences in study demands and mental health between universities and educational programmes, but we have no reason to suspect that the outcomes (exhaustion out and anxiety) is associated with which university or educational programme a student attend. Age is often an important determinant for response rate, but we did not find a significantly different mean age among the responders, compared to non-responders.

The cross-sectional design of our study means that causality cannot be established. A large number of longitudinal studies have illustrated that high demands predict psychological well-being, depression and stress-related disorders (De Lange, Taris, Kompier, Houtman, \& Bongers, 2003; Häusser et al., 2010; Nieuwenhuijsen, Bruinvels, \& Frings-Dresen, 2010). Therefore, most crosssectional analyses on psychosocial environments and health commonly consider strenuous conditions to cause detrimental health. There is, however, some evidence of a reversed relationship, for example, that persons with exhaustion or depression overestimate demands (Daniels \& Guppy, 1997; Glickman, Tanaka, \& Chan, 1991). Due to our study design, relationship directions cannot be established.

\subsection{Strengths}

Studies examining workload in students, with well-validated instruments that are frequently used when investigating stressing conditions, are almost completely lacking (Robotham, 2008; Robotham \& Julian, 2006). We also investigated social support, a well-known factor in occupational health studies, which rarely has been assessed among students. Although including this variable did not lower effects from study demands, support was still related to lower exhaustion and anxiety, illustrating the importance of a positive social climate in a student setting.

Another advantage of this study is that the analyses are stratified by gender. Previous literature on student health largely lacks studies on possible differences between stressing study demands and health between men and women (Robotham, 2008; Robotham \& Julian, 2006). This is surprising, as research in occupational health has shown that both psychosocial exposure and pathways between 
such exposure and health may differ between genders (Arbetsmiljöverket, 2016; Härenstam, 2009; Waldenström \& Härenstam, 2008). The motivation for lack of gender stratification is unknown, but perhaps there is a presumption that psychosocial exposures are more homogeneous in a university setting, compared to working life. Our stratified analyses, thus, illustrate that gender differences in exposure to psychosocial factors and mental health in higher education students should be further investigated.

When investigating psychosocial variables and health, personality traits are sometimes perceived as more dominant causes for illness than stressing exposure. It has also been argued that in an educational situation, with constant and prolonged evaluations, traits such as performance-based self-esteem are amplified (Schafer, 1992). However, such discourse diminishes effects from structural factors and interactive processes between the individual and organization. It is, thus, a strength in this study that analyses are adjusted for performance-based self-esteem, highlighting relationships between study demands and mental ill health, even when taking a relevant personality factors into consideration. As such, this study contributes to the evidence of, not only of high prevalence of mental ill health in higher education students, but foremost that study demands, even when adjusting for several confounders and established positive variables such as social support, are strongly related to adverse mental health.

\subsection{Conclusions}

Our results highlight study demands as a seemingly important factor for increased exhaustion and anxiety in teacher education students. Most higher education constitutes an intense workload, since it is preparing the students for future professions, and it may be that strenuous study demands are inevitable. Still, future studies, perhaps using qualitative methods, would benefit the state of knowledge regarding links between psychosocial study conditions and mental health, which could enhance precision in health interventions.

\section{Acknowledgement}

This work was supported by the Swedish Research Council for Health, Working Life and Welfare under Grant (number 2013-1517).

\section{References}

Abouserie, R. (1994). Sources and levels of stress in relation to locus of control and self esteem in university students. Educational psychology, 14(3), 323-330.

AFA-Insurance. (2016). Psykiska diagnoser i kontaktyrken inom vård, skola och omsorg. AFA-försäkring .

Akademihälsan. (2014). Akademihälsan Studenthälsovård Årsrapport 2014. Retrieved from

Aktekin, M., Karaman, T., Senol, Y. Y., Erdem, S., Erengin, H., \& Akaydin, M. (20o1). Anxiety, depression and stressful life events among medical students: a prospective study in Antalya, Turkey. Medical education, 35(1), 12-17.

Andrews, B., \& Wilding, J. M. (2004). The relation of depression and anxiety to life-stress and achievement in students. British Journal of Psychology, 95(4), 509-521.

Arbetsmiljöverket. (2016). Kvinnors och mäns arbetsvillkor. Rapport, 2016: 2.

Bewick, B., Koutsopoulou, G., Miles, J., Slaa, E., \& Barkham, M. (2010). Changes in undergraduate students' psychological well-being as they progress through university. Studies in Higher Education, 35(6), $633-645$.

Dahlin, M. (2007). Future doctors: Mental distress during medical education: cross-sectional and longitudinal studies: Institutionen för klinisk neurovetenskap/Department of Clinical Neuroscience.

Dahlin, M., Joneborg, N., \& Runeson, B. (2005). Stress and depression among medical students: A cross-sectional study. Medical education, 39(6), 594-604.

Dahlin, M., Joneborg, N., \& Runeson, B. (2007). Performance-based self-esteem and burnout in a cross-sectional study of medical students. Medical Teacher, 29(1), 43-48. 
Dahlin, M. E., \& Runeson, B. (2007). Burnout and psychiatric morbidity among medical students entering clinical training: a three year prospective questionnaire and interview-based study. BMC Medical education, 7(1), 1.

Daniels, K., \& Guppy, A. (1997). Stressors, locus of control, and social support as consequences of affective psychological well-being. Journal of occupational health psychology, 2(2), 156.

De Lange, A. H., Taris, T. W., Kompier, M. A., Houtman, I. L., \& Bongers, P. M. (2003). " The very best of the millennium": longitudinal research and the demand-control-(support) model. Journal of occupational health psychology, 8(4), 282.

Dyrbye, L. N., Thomas, M. R., \& Shanafelt, T. D. (2006). Systematic review of depression, anxiety, and other indicators of psychological distress among US and Canadian medical students. Academic Medicine, 81(4), 354-373.

Eller, N. H., Netterstrom, B., Gyntelberg, F., Kristensen, T. S., Nielsen, F., Steptoe, A., \& Theorell, T. (20o9). Workrelated psychosocial factors and the development of ischemic heart disease: a systematic review. Cardiol Rev, 17(2), 83-97. doi:10.1097/CRD.obo13e318198c8e9

Försäkringskassan. (2010). Långtidssjukskrivna. Beskrivande statistik 1999-2009. Socialförsäkringsrapport, $2010: 16$. Retrieved from http://www.forsakringskassan.se/wps/wcm/connect/o72d733c-5078-40oo-a8ooe3df662118ec/socialforsakringsrapport_2010_16.pdf?MOD=AJPERES

Galdas, P. M., Cheater, F., \& Marshall, P. (2005). Men and health help-seeking behaviour: literature review. Journal of advanced nursing, 49(6), 616-623.

Garlow, S. J., Rosenberg, J., Moore, J. D., Haas, A. P., Koestner, B., Hendin, H., \& Nemeroff, C. B. (20o8). Depression, desperation, and suicidal ideation in college students: results from the American Foundation for Suicide Prevention College Screening Project at Emory University. Depression and anxiety, 25(6), 482488.

Gavish, B., \& Friedman, I. A. (2010). Novice teachers' experience of teaching: A dynamic aspect of burnout. Social Psychology of Education, 13(2), 141-167.

Gillander Gadin, K., \& Hammarström, A. (2003). Do changes in the psychosocial school environment influence pupils' health development? Results from a three-year follow-up study. Scandinavian journal of public health, 31(3), 169-177.

Glickman, L., Tanaka, J. S., \& Chan, E. (1991). Life events, chronic strain, and psychological distress: Longitudinal causal models. Journal of Community Psychology, 19(4), 283-305.

Hall, E. M. (1992). Double exposure: the combined impact of the home and work environments on psychosomatic strain in Swedish women and men. International Journal of Health Services, 22(2), 239-260.

Hallsten, L., Josephson, M., \& Torgén, M. (2005). Performance-based self-esteem: A driving force in burnout processes and its assessment.

Härenstam, A. (2009). Exploring gender, work and living conditions, and health-suggestions for contextual and comprehensive approaches. Scand J Work Environ Health, 127-133.

Häusser, J. A., Mojzisch, A., Niesel, M., \& Schulz-Hardt, S. (2010). Ten years on: A review of recent research on the Job Demand-Control (-Support) model and psychological well-being. Work E stress, 24(1), 1-35.

Johnson, J. V., \& Hall, E. M. (1988). Job strain, work place social support, and cardiovascular disease: a crosssectional study of a random sample of the Swedish working population. American journal of public health, $78(10), 1336-1342$

Karasek, R., Brisson, C., Kawakami, N., Houtman, I., Bongers, P., \& Amick, B. (1998). The Job Content Questionnaire (JCQ): an instrument for internationally comparative assessments of psychosocial job characteristics. Journal of occupational health psychology, 3(4), 322.

Karasek, R. A. (1979). Job demands, job decision latitude, and mental strain: Implications for job redesign. Administrative science quarterly, 24(2), 285-308.

Karasek, R. A. (1992). Healthy work: stress, productivity, and the reconstruction of working life. LaVergne, USA: Basic books.

Khan, F., Yusoff, R., \& Khan, A. (2014). Job demands, burnout and resources in teaching a conceptual review. World Applied Sciences Journal, 30(1), 20-28.

Lager, A. (2009:8). Varför drabbas kvinnor oftare av oro, ångest och depression - En kunskapsöversikt Retrieved from Östersund:

Lidwall, U. (2015). Vård och omsorg har flest nya sjukfall i Sverige. Korta analyser 2015:1. Retrieved from Stockholm:

Lisspers, J., Nygren, A., \& Söderman, E. (1997). Hospital Anxiety and Depression Scale (HAD): some psychometric data for a Swedish sample. Acta Psychiatrica Scandinavica, 96(4), 281-286.

Lundgren-Nilsson, Å., Jonsdottir, I. H., Pallant, J., \& Ahlborg, G. (2012). Internal construct validity of the ShiromMelamed Burnout questionnaire (SMBQ). BMC Public Health, 12(1), 1. 
Melamed, S., Kushnir, T., \& Shirom, A. (1992). Burnout and risk factors for cardiovascular diseases. Behavioral Medicine, 18(2), 53-6o.

Nieuwenhuijsen, K., Bruinvels, D., \& Frings-Dresen, M. (2010). Psychosocial work environment and stress-related disorders, a systematic review. Occupational medicine, 6o(4), 277-286.

Norlund, S., Reuterwall, C., Höög, J., Lindahl, B., Janlert, U., \& Birgander, L. S. (2010). Burnout, working conditions and gender-results from the northern Sweden MONICA Study. BMC Public Health, 1o(1), 326.

Roberts, R., Golding, J., Towell, T., \& Weinreb, I. (1999). The effects of economic circumstances on British students' mental and physical health. Journal of American College Health, 48(3), 103-109.

Robotham, D. (2008). Stress among higher education students: towards a research agenda. Higher Education, 56(6), 735-746.

Robotham, D., \& Julian, C. (2006). Stress and the higher education student: a critical review of the literature. Journal of further and higher education, 30(02), 107-117.

Rotenstein, L. S., Ramos, M. A., Torre, M., Segal, J. B., Peluso, M. J., Guille, C., . . Mata, D. A. (2016). Prevalence of depression, depressive symptoms, and suicidal ideation among medical students: a systematic review and meta-analysis. Jama, 316(21), 2214-2236.

Saltin, B., \& Rowell, L. B. (1980). Functional adaptations to physical activity and inactivity. Paper presented at the Federation proceedings.

Sanne, B., Mykletun, A., Dahl, A. A., Moen, B. E., \& Tell, G. S. (2005). Testing the job demand-control-support model with anxiety and depression as outcomes: The Hordaland Health Study. Occupational medicine, $55(6), 463-473$.

Sanne, B., Torp, S., Mykletun, A., \& Dahl, A. A. (2005). The Swedish Demand-Control-Support Questionnaire (DCSQ): Factor structure, item analyses, and internal consistency in a large population. Scandinavian journal of public health, 33(3), 166-174.

Schafer, W. E. (1992). Stress management for wellness.

Shapiro, S. L., Shapiro, D. E., \& Schwartz, G. E. (200o). Stress management in medical education: a review of the literature. Academic Medicine, 75(7), 748-759.

Sonmark, K., \& Modin, B. (2017). Psychosocial work environment in school and students' somatic health complaints: An analysis of buffering resources. Scandinavian journal of public health, 45(1), 64-72.

Stansfeld, S., \& Candy, B. (2006). Psychosocial work environment and mental health--a meta-analytic review. Scand J Work Environ Health, 32(6), 443-462.

Stewart-Brown, S., Evans, J., Patterson, J., Petersen, S., Doll, H., Balding, J., \& Regis, D. (20oo). The health of students in institutes of higher education: an important and neglected public health problem? Journal of Public Health, 22(4), 492-499.

Svensson, F., \& Berlin Kolm, S. (2017). Tidiga avhopp från högskolan-analyser av genomströmning på de tio största yrkesexamensprogrammen. In: Stockholm: Swedish Higher Education Authority.

Waldenström, K., \& Härenstam, A. (2008). Does the job demand-control model correspond to externally assessed demands and control for both women and men? Scandinavian journal of public health, 36(3), 242249.

Van der Doef, M., \& Maes, S. (1999). The job demand-control (-support) model and psychological well-being: a review of 20 years of empirical research. Work E stress, 13(2), 87-114.

Ware Jr, J. E., \& Sherbourne, C. D. (1992). The MOS 36-item short-form health survey (SF-36): I. Conceptual framework and item selection. Medical care, 473-483.

Vasalampi, K., Salmela-Aro, K., \& Nurmi, J.-E. (2009). Adolescents' self-concordance, school engagement, and burnout predict their educational trajectories. European psychologist, 14(4), 332-341.

Zoccolillo, M., Murphy, G. E., \& Wetzel, R. D. (1986). Depression among medical students. Journal of affective disorders, 11(1), 91-96. 